\title{
THE FUTURE OF COMPUTERS IN ANAESTHESIA *
}

\author{
EDWard Llewellyn Thomas, M.D., C.M., P.eng. $\dagger^{\prime}$
}

ANAESTHEsia IS EFFECTIVE, safe-and complicated. The introduction of computers would promise to make it more complicated; can they make it safer or more effective? Not today perhaps, but the increasing complexity of surgical procedures is requiring anaesthetists to measure more and more variables, handle more and more information, control more and more the patient's physiological status, and they are already approaching the limit of what they can do unaided. I suggest that soon they will have to turn to the computer for help, as so many other people have had to do.

For anaesthetists are not the only ones caught in our scientific and technological explosion. Airline captains, air traffic controllers, chemical engineers, and the managers of space shoots are all examples of men who have to control complex, rapidly changing, and potentially unstable systems whose futures cannot be predicted with sufficient accuracy to be pre-programmed, that is to allow the setting up of a fixed plan of action beforehand. Our modern world often looks like a race between two groups, the one continuously devising more complex, more rapidly acting systems, the other attempting to devise methods to keep them controllable. When such systems get ahead of the means of control we have debacles such as the northeast power failure of November 1965.

In our own field it is the surgeons who, with the enthusiastic support of medical specialists and scientists, are devising more complex procedures, and using more complicated tools. Within a few years they will, I think, be able to pass every human system, except the cNs, over to the care of life-support machines and anaesthetists, while they carry out their heroic programmes of replacement and repair. The anaesthetists themselves are adding to the complexity by using a greater variety of drugs and anaesthetic agents which require a wider spectrum of continuous current information about the patient's status for their successful use.

To see how computers will enter into all this I think we must first look at the basic problem of controlling a complex and potentially unstable system in real time.

\section{The Control of Complex Systems}

One of the major tools of our modern technology is the concept of a "system." This represents the realization that in many fields of human endeavour a large number of different components, both human and machine, are combined together

'Presented at the Annual Meeting, Canadian Anaesthetists' Society, May 13-16, 1968.

†Dr. Thomas is Associate Director, Institute of Bio-Medical Electronics, Professor of Pharmacology, Associate Professor of Electrical Engineering, and Associate, Department of Anaesthesia, University of Toronto.

Can. Anaes. Soc. J., vol. 15, no. 6, November 1968 
to achieve some common goal. A pilot and a high performance aircraft, for example, together comprise a complex man-machine system, and one essential aspect of the system is the rapid flow of information between the machine and the pilot. The pilot can be considered as "extending" into the machine. His own senses are insufficient; he sees by radar, hears by radio, his attention is focussed on his instruments rather than the sky around him or the ground beneath him. He communicates with his machine by servo controls rather than using his muscular force to haul on joy-sticks. The task of flying such an aircraft unaided is beyond human capabilities, and he is assisted by a number of machines and computers, such as the auto-pilots.

An anaesthetist is also a controller of a complex system. When he anaesthetizes a patient with the aid of muscle relaxants and autonomic blockers he is opening some of the control loops which the body uses to maintain physiological homeostasis. $\mathrm{He}$ is in effect assuming the role of the body's own controllers and therefore the responsibility for maintaining homeostasis.

\section{Decisions in Real Time}

One important aspect of this role as a controller is that he has to make decisions in real time. Once he has started to give an anaesthetic he is committed to a series of decisions and actions which he has to adjust from moment to moment to meet the changing status of his patient. He cannot postpone decision by asking for another X-ray, or another laboratory test, or adopt a policy of watchful waiting. Like the engineer controlling the changing trajectories of a space vehicle, he is making dynamic decisions to meet changes in a situation which can be forecast in terms of probability but not of certainty. He knows what is likely to happen, not what will happen. There are too many alternatives for him to have a complete programme already prepared for each one.

This is quite unlike the role of the scientist who after he has planned and started an experiment does not interfere-it is scientific heresy for him to do so. In fact this obligation to interfere, to continuously attempt to "optimize" the system that he is controlling, is one of the marks of the professional man practising his profession. He is grappling with an uncertain future which can only be expressed in terms of conditional probabilities. He is continuously faced with making decisions based on new information-with the depressing certainty that some of his decisions will not be the best possible, and that he may be involved in further decisions to retrieve a deteriorating situation.

\section{INFORMATION AND DECISION}

Therefore, like all real time controllers, he needs a continuous flow of accurate up-to-date information about the system he is controlling to aid his decisions and to guide his actions. The information must be relevant, and he must know how accurate it is-that is, the nature of its statistical distribution, and the probability that it is correct.

The information we get is of two kinds. The first is semantic information 
involving subjective judgment information: "My wife is beautiful" or "This chap looks as if he's going into shock." This is the kind of information that we cannot express in any present scale of numbers and includes much of our "clinical" information and the information we use most in everyday life.

The other kind of information is selective information involving objective measurement: "My wife is $35-27-36$ " or "His blood pressure is $70 / 40$." It is certainly more important to know that a girl is beautiful or a patient is in shock than to know numbers. Nevertheless, when we have to control variables, such as blood pressure, which are measured as numbers, we need such selective information. Moreover it is the only kind of information that our instruments can measure.

The information must be relevant because irrelevant information is "noise" and interferes with our decision-making capabilities. Human beings, even anaesthetists, are basically single channel, and can only deal consciously with one variable at a time, switching rapidly from one to another when they have to deal with several. So irrelevant information delays us in our search for a decision. Unfortunately, often we are not sure what is relevant and what is not.

We must know how far we can trust our information. What is its distribution and standard deviation? What is its conditional probability? How much does its value depend upon other variables? For example, information about a patient's blood pressure needs to be compared with other cardiovascular measurements, such as heart rate, and we must ask whether he is usually hypotensive or hypertensive.

So we also need memory and recall. Human memory is a wonderful thing, but in general it is much better at remembering semantic than selective information; the shape of a girl's mouth rather than her telephone number.

\section{Date Analysis and Display}

Therefore the information about the patient's status must be relevant, accurate, and up-to-date. It must also be presented in a form that the anaesthetist can appreciate and utilize easily; it should not have to be converted by the anaesthetist in his head. For example, a patient's temperature in degrees Centigrade is not in the best form for most English-speaking physicians. It should be displayed to him so that he can see or hear it easily; in other words, he should not have meters, dials, cathode ray tubes, etc. scattered all over the patient and the operating room. There are lessons to be learned here from the aircraft cockpit. In earlier days meters were placed wherever there was a vacant space on the dashboard, and the pilot was left to search for the ones he needed at each particular phase of the flight. When the numbers and the speed of the aircraft increased, a pilot could obviously still be searching his instrument panel after this task had become irrelevant. Increased complexity forced on the designer the necessity of grouping the instruments and displays to suit the behaviour of the system and the visual needs of the pilot. He had to "facilitate information flow across the man-machine interface," in terms of the current jargon.

Even more important, the information must be up-to-date. The body's own controllers usually have short time constants; they are sensing blood gases now, 
not fifteen minutes ago. When the anaesthetist takes over their role he needs at least the same information and as quickly. At present he does not always get it. To return to the aircraft analogy, he is rather like a pilot whose gas gauge tells him the fuel reserves twenty minutes ago and his compass the heading fifty miles back; under these circumstances he would probably be wisest to fall back on his "clinical judgment," fly low, and look at the ground. He is certainly in no shape to set out across the Atlantic.

\section{Computer Capabilities}

A good pilot flying in good visibility over a familiar landscape in a slow singleengined aircraft can get along with very little in the way of instrumentation. A good anaesthetist can give an excellent anaesthetic for a simple procedure with very little beyond a rag and a bottle of ether. But neither of these situations applies any longer. Many of the requirements outlined in the previous paragraphs demand the use of devices to sense variables such as temperature, pressure, gas flows, and so on, together with the ability to calculate, normalize, and present the results of the calculations.

The modern computer can sense, store, and recall selective information. It can calculate, analyse, wam, predict, control, and train. Examples of these capabilities are shown in Table I. Some of these things it does very well indeed, in others its present performance is poor to mediocre. But the electronic computer is only some fifteen years old, and its capabilities have developed faster than those of any other of man's creations.

It is commonly said that all the digital computer can do basically is to add two numbers, compare two numbers, and remember numbers. This is true, but is rather like saying that all the neuron can do is to receive inputs and create an action potential if the inputs sum to some critical value. The digital computer

TABLE I

Some Uses for Computers in Anaesthesia

\begin{tabular}{ll}
\hline \hline \multicolumn{1}{c}{ Uses } & \multicolumn{1}{c}{ Examples } \\
\hline $\begin{array}{l}\text { Sense, display, store, and } \\
\text { recall information }\end{array}$ & $\begin{array}{l}\text { Physiological variables such as arterial and venous pressures } \\
\text { Blood } \mathrm{P}_{\mathrm{O}_{2}}, \mathrm{P}_{\mathrm{CO}_{2}, \mathrm{pH}, \mathrm{Na}, \mathrm{K}, \text { glucose, etc. }} \\
\text { Blood flow, e.g. cerebral blood flow } \\
\text { ECG, EEG, etc. } \\
\text { Anaesthetic blood gases } \\
\text { Cardiac output }\end{array}$ \\
Calculate and analyse & $\begin{array}{l}\text { Arterial venous differences in blood variables } \\
\text { Occurrence of abnormalities, e.g. arrhythmias }\end{array}$ \\
Warn & $\begin{array}{l}\text { Variables moving outside preset limits } \\
\text { Developing hypotension, hypoglycaemia, metabolic acidosis, etc. }\end{array}$ \\
Predict & $\begin{array}{l}\text { Rate of infusion fluids } \\
\text { Balance of anaesthetic gases }\end{array}$ \\
Oxygenation of blood & Simulation of anaesthetic situations \\
Train & Mathematical models \\
Plan complex procedures & Critical path techniques, PERT, etc.
\end{tabular}


can perform its simple basic functions at such a prodigious speed and in such vast quantities that it can perform logical operations which, when added together, give it such remarkable capabilities as playing a reasonable game of chess. Basically it remains an adding machine with a memory, but the new generation of computers now arriving are able to play variations on this theme which include making decisions about quite complex situations, and adjusting a system which is operating in an unpredictable environment so that it gives optimum results. It is these capabilities which have made it an essential part of the modern airliner, the modern continuous flow chemical plant, and the control of a space vehicle. It is these capabilities which will make it an essential part of the complex surgical procedures of the future.

Most of us are already familiar with the more common present uses of computers, such as working out problems in statistics and storing data. These have obvious application in anaesthesia, in the storage of patients' histories, laboratory findings, etc., as they have in other branches of medicine. We are also aware of the increasing use of machines to monitor patients as exemplified in the acute coronary units.

The future use of the computer in anaesthesia lies in the marrying of these two groups of facilities for on-line use in the operating room, with the added facility to control, a facility not yet apparent elsewhere in medicine, but being developed in the control of continuous flow industrial chemical processes. The role of sensing and transducing is obvious, although the actual sensor may be somewhat mysterious. But I want to examine a few of the developing abilities of the computer in the area of decision and control. I would emphasize that these are not yet practical and it will probably be some years before they are ready for consideration by anaesthetists, but I am convinced that they, or something like them, will be coming into anaesthetic use within the next ten years.

\section{Optumization}

This ugly word describes the process of adjusting a system until it is performing as close to its "best" as possible. The aircraft is flying the shortest, or safest, or cheapest, route between two points. The chemical plant is producing the maximum possible amount of some product from the raw materials available, or producing the mix of products giving the highest profit from the raw materials. In the anaesthetic example it might be producing the maximum muscle relaxation consistent with adequate oxygenation, etc.

Human beings can optimize very well in simple situations, or in those situations which can be forecast with great mathematical accuracy. If the environment is constant, and the raw materials always of exactly the same type-in fact, if everything remains exactly the same-then the series of processes in a chemical plant can be worked out beforehand for maximum yield, either by theoretical calculations or by suitable experiments, the process can be set up to run, and the operator will know it will be as efficient as possible. In short, the process can be pre-programmed.

But such circumstances often do not apply in real life. Conditions change, and 
many of these changes are unpredictable. The system must be able to alter to meet them, and the controller must be constantly adjusting the behaviour of the system to keep it moving towards the desired goal. In simple situations, steering an automobile from one place to another for example, this remains comparatively easy as the environmental changes are local and the operator can correct for them by simple processes. It becomes more difficult in flying an aircraft with a cross wind of changing velocity and direction. The pilot then has to act as a navigator, collecting data, calculating, and changing course and speed to meet these changes.

As new changing variables are introduced the operator often has to abandon his attempt to maintain the best possible behaviour of the system he is controlling, and settle for some compromise. This is usually because he cannot get sufficient information about all the important variables involved, and because he has not time to carry out the calculations necessary to pick the very best course of action. Those who know some calculus will remember that obtaining the best possible value for something or other often involved finding the point at which the slope of a curve became zero, that is of equating to zero the second differential of the equation describing the curve. Very few of us can solve second order differential equations while trying to fly an aircraft or give an anaesthetic, even if the requisite equations can be written. In a very few examples these equations can be defined and worked out beforehand; for example, the range of an artillery piece against muzzle elevation and charge, or oxygenation against haemoglobin, and the curves plotted ready for us to use, or tables prepared. But these cases only apply when there are a few variables.

A computer may be able to solve such equations with several variables at great speed. This offers us the opportunity of trying to control for the best, rather than accept a compromise. One such example in anaesthesia might be to optimize cardiac output against blood pressure.

The other, and much more practical method in most cases, is a modification of what we usually do when we try to optimize a system. We make small changes in one variable, note the results of the change, and then make a second change depending on the effects of the first. We increase the flow of an anaesthetic gas, note the changes in the patient, and then give more or less depending on what we see.

The snag is that we should hold everything else constant while we make this change, and the change must be so small that we can retract it if the response is in the wrong direction. We should, in theory, optimize one variable, such as the anaesthetic gas, and then holding that constant, move rapidly on to another variable, such as oxygen flow, and optimize that. Our practical problem is that we cannot carry out trials on one variable fast enough to really optimize it while the others are constant, and that we become hopelessly confused if there are more than two or three variables.

Now there are at least a dozen important variables to be observed in a patient anaesthetized with a gas mixture and muscle relaxants. It is impossible to adjust everything for the "best" possible patient status, even when we know what that is. So we quite rightly accept a compromise, and use "safety" as our touchstone. If, however, the effect of every adjustment we make is immediately presented 
to us in a form we can appreciate, then we can do better. If, for example, we have some method of changing lung compliance and could watch the pressurevolume loop on a CRT, we could adjust for the compliance we want, back-tracking when we have passed it.

We can take this a stage further, for obviously compliance is only of interest to the extent that it tells us something about the status of the patient's respiratory system. We would like to see it incorporated in a more general index of respiratory effectiveness, that is, combined with other variables to give an index we can optimize, though still leaving us free to scrutinize each variable separately if we wish to.

As soon as we start to attempt such procedures as normalizing data or allowing for interactions between variables or calculating trends, we have to carry out mathematical calculations rapidly, and we need fast calculators which can be set up beforehand to perform the procedures we want, and they must have methods of recording the data and findings and produce it for our inspection or calculation when required. They must also be capable of carrying out a number of different calculations or programmes and changing from one to the other. Briefly, we require a digital computer.

\section{Decision Making}

Optimization, and in fact the control of a system at all, basically involves gathering information, thinking about it, and then making a decision to do something, or to refrain from doing something. Subconsciously we continuously consider the chances of various possibilities to all the alternate effects of our actions, and then pick the one which gives us the highest chance of success. Occasionally we actually think in figures, for example what is the probability of this patient having an abnormal anticholinesterase before we administer succinylcholine? And we revise that conditional probability if we learn that one of the patient's parents remained paralysed for two hours when given an anaesthetic. But most of the time we do not think in terms of statistics, because we do not have the data, and make our judgment based on our general experience and express it in words like "safe" or "dangerous" or "last chance."

But we can have even less confidence in these generalized words as the number of interacting variables increases. It is here that the computer has the future potential for helping us, even if only by recording all the drugs and procedures which are going on and then flashing gently, "Fourteen anaesthetists have built up to the combination you are about to complete, and three of them are now involved in litigation."

\section{Computer Assistance}

What I want to bring out is that the computer has the potentialities for acting as a fast calculating, fast sensing, and patient colleague with a prodigious memory, a limited capability to predict about variables with which it is equipped to deal, and no imagination. It may be possible to give it responsibilities for the 
control of some simple variables to relieve the anaesthetist of routine tasks so he can do more important ones, or to watch some variables and warn him if they pass outside limits he has set. But to talk of computers replacing any skilled professional, be it anaesthetist, pilot, or engineer, is fatuous. What the computer is doing is allowing these unfortunate individuals to assume heavier and heavier loads of responsibilities and make harder and harder decisions. Remember that when chloroform was the only anaesthetic you did not have to make any decision about what anaesthetic mix to use, however many of the patient's physiological variables you knew. The choice between ether and chloroform was limited. Nobody asked the anaesthetist to keep the patient healthy, relaxed, and unconscious while they changed his heart and lungs and cleaned out his arteries, and maybe transferred a kidney from somebody in the next room who must reach exactly the right operative stage at some unpredictable time during the next six hours.

Nor did they expect patients to be held tottering on the brink of life for days on end; nor did they find out all about his medical history so that surgical and anaesthetic decisions could be made beforehand. But these things are now being tentatively asked and will soon be demanded. The anaesthetist of the future is likely to turn to either a computer or a psychiatrist for help.

\section{Summary}

The anaesthetist of the future will turn to computers to assist him in the increasingly complicated surgical procedures for which he will have to supply anaesthesia. This reflects an important facet of anaesthesia, the fact that the anaesthetist has to make complex decisions in real time. $\mathrm{He}$ is essentially a controller of a complex system and by opening many of a patient's own control loops he assumes responsibility for maintaining the patient's homeostasis. To be successful in this task he needs accurate and up-to-date data presented to him in the way he can best appreciate and use it to aid him in his control decisions.

Computers can aid the anaesthetist in planning complex procedures, in preanaesthetic evaluation, on-line in the operating room during anaesthesia, and in the recovery room period. They can help him with his statistics and his training. But the most important aid will be during the anaesthesia itself, for it is then that the anaesthetist has to make his most rapid and difficult decisions. The computer can help him by its ability to sense, store, and recall information, to calculate and analyse, to warn, predict, and control. All these abilities are only aids to the anaesthetist and cannot replace his skill and judgment.

Present computers and machines have only limited capabilities, but they are improving rapidly and in the future have the potential of serving the anaesthetist as a tireless and patient colleague with an excellent "head for figures"-but with limited judgment and no initiative.

\section{RÉSUMÉ}

L'anesthésiste de l'avenir va demander de l'aide aux cerveaux électroniques au cours des opérations de plus en plus compliquées où il sera appelé à donner 
l'anesthésie. Ceci fait voir un aspect important de l'anesthésie : le fait que l'anesthésiste doit prendre, instantanément, des décisions complexes. Essentiellement, il est le contrôleur d'un système complexe et, de plus, parce qu'il ouvre un bon nombre de circuits que contrôle le malade, il prend la responsabilité de maintenir l'homéostase du malade. Pour réussir dans cette tâche, il lui faut des données récentes et précises, données bien présentées qu'il peut utiliser lorsqu'il doit prendre des décisions importantes.

Les calculatrices peuvent aider l'anesthésiste à tout organiser lors d'opérations compliquées, à l'évaluation préanesthésique, au cours de l'anesthésie et de l'opération et durant les suites opératoires. Elles peuvent lui rendre service pour ses statistiques et sa formation. Le plus important atout qu'elles apportent, c'est au cours de l'anesthésie qu'elle le procurent, alors que l'anesthésiste doit prendre les plus rapides et les plus difficiles décisions. Les calculatrices peuvent l'aider parce qu'elles peuvent apprécier, emmagasiner et se rappeler un renseignement; elles peuvent calculer, analyser, mettre en garde, prédire et contrôler. Toutes ces différentes possibilités ne sont que des adjuvants pour l'anesthésiste; elles ne peuvent pas remplacer sa dextérité ni son jugement.

Actuellement, les calculatrices et les diverses machines n'ont que des possibilités limitées, mais elles s'améliorent rapidement et, à l'avenir, il est possible qu'elles puissent devenir pour l'anesthésiste un collègue patient et infatiguable possédant pour les chiffres des dons excellents, mais leur jugement est bien borné et elles n'ont aucune initiative. 